\title{
Characterization of Korean handmade papers collected in a Hanji reference book
}

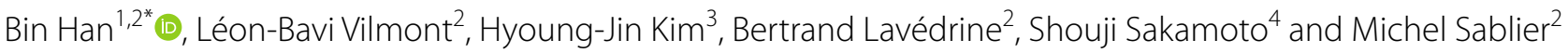

\begin{abstract}
Korean hand papermaking is a renowned cultural tradition in the Korean peninsula. It is still practiced while scientific analysis of paper itself from a large data set is rare. In this study, a set of more than three hundred Korean handmade papers, collected in a reference collection book Hanji: Korean handmade paper, were chemically investigated, and their property data such as colour, pH, grammage, thickness, tensile strength, folding endurance were statistically analysed in order to determine general features for Korean papers. The influence of different paper sheet formation methods (Heullimtteugi vs Gadumtteugi) were revealed by multivariate data analysis and the chemical profiles of raw materials were studied by pyrolysis-gas chromatography/mass spectrometry (Py-GC/MS). The Korean handmade paper samples display colour gamut in the colour space $L^{*}(69.9-95.9), a^{*}[(-3)-3], b^{*}(0-20)$, most have neutral/alkaline pH values. Paper density, fiber orientation and physical properties are influenced by the sheet formation techniques. For instance, Gadumtteugi tends to produce papers with strong fiber orientation while Heullimtteugi produces papers with more evenly distribution of fibers. In addition, Py-GC/MS analysis results show that paper mulberry fibers contain less intensity lignin monomers and more terpenic compounds in comparison with gampi and mitsumata fibers. This study provides paper analysis from large sample set, statistics reveal that the material preparing and making craft determined the paper structure which reflected in their physical properties. These properties influenced paper performance and applications in art creations as well as relics conservation and restoration. The characterized paper sample database could be used for handmade paper studies in East Asian region. Consequently, this study contributes to a better understanding of contemporary Hanji properties as well as improves knowledge on handmade papers from the Korean peninsula.
\end{abstract}

Keywords: Korean handmade papers, Heullimtteugi, Gadumtteugi, Multivariate data analysis, Py-GC/MS, Lignin monomers

\section{Introduction}

Crafts of hand papermaking are listed as intangible cultural heritage and handmade papers were commonly used in art creations as well as relics conservation and restoration. Different traditions and crafts explored various plant materials for papermaking through history both chronologically and geographically [1-3]. The variety of material and crafts process in East Asian countries

\footnotetext{
*Correspondence: bin.han@ucas.ac.cn

1 Department of Archaeology and Anthropology, School of Humanities, University of Chinese Academy of Sciences, Beijing 100049, China Full list of author information is available at the end of the article
}

makes papers that have different properties, such as Chinese Xuan paper [4, 5], Japanese Washi [6, 7] and Korean Hanji [8-11]. Among them, the Korean traditional handmade paper, commonly refers as Hanji, is a traditional symbol and heritage treasure from the Korean peninsula [10].

Hanji is primarily used as the writing, painting, and printing substrate and Korean crafters used Hanji to repair tears and fill gaps on paper, manuscripts, paintings, and books due to its good properties and durability. Traditional Hanji is permanent and it can last for more than 1000 years when preserved in proper conditions [8, 12, 13]. The ancestral Hanji craft is renowned due to its

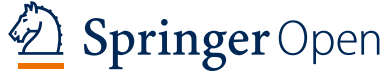

(c) The Author(s) 2021. Open Access This article is licensed under a Creative Commons Attribution 4.0 International License, which permits use, sharing, adaptation, distribution and reproduction in any medium or format, as long as you give appropriate credit to the original author(s) and the source, provide a link to the Creative Commons licence, and indicate if changes were made. The images or other third party material in this article are included in the article's Creative Commons licence, unless indicated otherwise in a credit line to the material. If material is not included in the article's Creative Commons licence and your intended use is not permitted by statutory regulation or exceeds the permitted use, you will need to obtain permission directly from the copyright holder. To view a copy of this licence, visit http://creativecommons.org/licenses/by/4.0/. The Creative Commons Public Domain Dedication waiver (http://creativeco mmons.org/publicdomain/zero/1.0/) applies to the data made available in this article, unless otherwise stated in a credit line to the data. 
oriental gracefulness. During its making, bast fiber from paper mulberry (Broussonetia spp.) is used as the main raw material while other plant fibers were also used such as gampi and mitsumata. The process of raw material and making methods influenced Hanji properties and performance [14-16]. The sheet formation of Hanji involves two main methods, Heullimtteugi (Oebal) and Gadumtteugi (Ssangbal) which differs in the mould shape and wet formation process [17]. Heullimtteugi (single mould) is an original Korean method in which the mould is suspended by a single string. The fiber stock is firstly dipped onto the paper mould and flow away in the forward direction and subsequently repeated several times. The paper stock was scooped again and rhythmically rocked from side to side that enables fiber to accumulate in crisscross layers without dominant fiber orientation $[15,18]$. The Gadumtteugi (double mould) usually employs a front-water approach that drives the mould forward and then backwards that takes five or six swings until a desired thickness is formed across the mould screen and produced paper with evident fiber orientation $[17,18]$.

Strong, stable and durable handmade Hanji has long been used in book and paper conservation in the Korean peninsula [17]. Moreover, Hanji has also gradually drawn attention from art practitioner and conservators worldwide and some European conservators even have established professional links such as Group $130^{\circ}$ to test and facilitate the use of Hanji as conservation materials [19, 20]. A comprehensive knowledge about the type of paper, the manufacturing techniques and the subsequent physical properties, helps to promote their application in the decoration, art creation as well as in the conservation and restoration process [19]. However, most of Hanji characterization studies were based on small set of samples and therefore it is difficult to have an overall knowledge and general cognition of contemporary Hanji. And research was still lacking for Hanji studies in the areas of observation, analysis, case studies, and status survey [21].

Material characterization can provide useful information on paper composition and conservation state [2229]. Investigation on traditional East Asian handmade papers employed a variety of material characterisation methods such as physical property measurements [22, 23, 30], microscopy observation [31-33] and chemical composition analysis [34-36]. On-line pyrolysis hyphenated with gas chromatography/mass spectrometry (PyGC/MS) is among the most frequently used techniques for cellulosic material studies due to simple preparation with minimum quantity required [37-39]. Its practical application on Japanese and Chinese handmade papers was previously explored as a new approach for East Asian handmade paper characterization [3, 40, 41].
In the aim of gaining comprehensive knowledge on Hanji properties, we investigated a large set of samples collected in a Hanji reference book for an overview features of modern Hanji. The influence of making craft on the paper properties were analysed. Pyrolysis-gas chromatography/mass spectrometry (Py-GC/MS) analysis has been conducted on Hanji raw materials of paper mulberry, gampi and mitsumata fibers for their chemical profile characterization. Such material analysis approaches are for the first time investigated with well edited Hanji samples in a large quantity.

\section{Materials and methods Materials}

A four-volume reference paper collection book Hanji, Korean handmade paper was edited by prof. HyoungJin Kim (Kookmin University, Seoul) [42]. This reference collection provides 309 Hanji samples from 26 paper mills across Republic of Korea (Additional file 1: Figure S1; Table S1). It includes valuable information not only on the papermaking process but also provides property information on these papers (Fig. 1; Additional file 1: Table S1). This reference collection forms a well edited reference source that reflects the modern Korean handmade papers. Consequently, the materials used in this investigation consist of 309 Hanji samples in this fourvolume reference sample book Hanji, Korean handmade paper. General data attached in the Hanji reference book was listed in table S1 in the supplementary material on the paper samples for which analyses were performed. A reference of Japanese kozo (Broussonetia kazinoki Siebold \& Zucc.) paper prepared following the Japanese traditional processes was also used in the Py-GC/MS analysis.

\section{Methods \\ Statistical data analysis}

General paper property data on the samples included in the four-volume Hanji reference book have been analysed and attached in the reference sample book. The details of certain property data as well as testing conditions are listed in Additional file 1: Table S1. The data on papermaking methods, $\mathrm{pH}$ values, mechanical property (e.g., grammage, thickness, tensile strength, folding endurance) and colour information of handmade papers collected in the reference book are statistically analysed using Microsoft Excel, Unscrambler X (Version 10.4) software from CAMO Software AS.

\section{Microscopy observation}

Orientation of the fibers in the paper is observed directly under a digital microscope (VHX-1000, Keyence, Japan). 


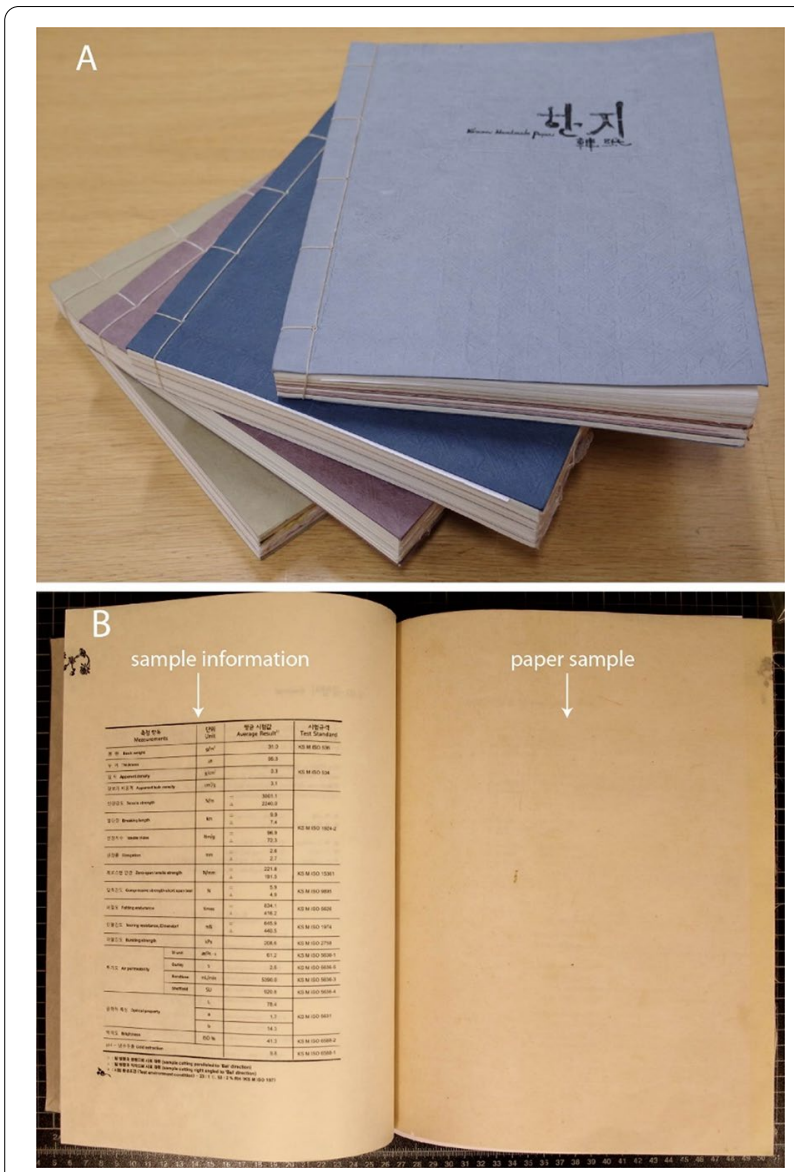

Fig. 1 A The four-volume of reference paper sample collection book Hanji, Korean handmade paper in which provides 309 paper samples with making information and property measurements (B)

The samples were placed directly onto the microscope platform in light reflection mode.

\section{Py-GC/MS analyses}

Py-GC/MS analyses were performed using a vertical micro-furnace-type pyrolyzer PY-2020iD (Frontier Lab, Fukushima, Japan) directly connected to the injection port of a Shimadzu QP2010 gas chromatograph linked with a Shimadzu QP2010Plus quadrupole mass spectrometer (Shimadzu, Champs-sur-Marne, France). The sample was placed in a stainless steel sample cup. The paper samples were weighted with an XP2U Ultra Micro Balance (Mettler Toledo, Viroflay, France). Typical quantities of paper used in this work were ca. $100 \mu \mathrm{g}$ weighted with the microbalance. The sample cup was placed on top of the pyrolyzer at near ambient temperature. The sample cup was introduced into the furnace at $500{ }^{\circ} \mathrm{C}$, and then the temperature program of the gas chromatograph oven was started. The Py-GC interface was held at $320^{\circ} \mathrm{C}$. Chromatographic separation was carried out on a
Frontier Lab DB5-ms 5\% phenyl-95\% dimethyl polysiloxane fused silica capillary column (30 m length, $0.25 \mathrm{~mm}$ inner diameter and coated with a $0.25 \mu \mathrm{m}$ film thickness). The oven temperature was initially held $3 \mathrm{~min}$ at $40{ }^{\circ} \mathrm{C}$, and then ramped at $5{ }^{\circ} \mathrm{C} \mathrm{min}{ }^{-1}$ to $325^{\circ} \mathrm{C}$, where it was held for $10 \mathrm{~min}$. The total duration of GC analysis was 70 min. The helium carrier gas Alphagaz 1 (Air Liquide, France) was used in the linear velocity mode $\left(1 \mathrm{~mL} \mathrm{~min}{ }^{-1}\right)$. The injector was held at $280^{\circ} \mathrm{C}$ and used in split mode (1:10 of the total flow). The mass spectrometer was operated at $5000 \mathrm{u} \mathrm{s}^{-1}$, with a scan range from 50 to $500 \mathrm{u}$, using electron ionization at $70 \mathrm{eV}$. The interface was kept at $300^{\circ} \mathrm{C}$ and the MS source at $200^{\circ} \mathrm{C}$. The mass spectra of the pyrolysis products were recorded using the average spectrum + average and subtract spectrum modes in the Shimadzu GCMSsolution software. Identifications were achieved on the basis of EI mass spectra by interpretation of the main fragmentations and using the NIST MS library (2011).

\section{Results and discussion Overview features}

This study investigates a large set of various contemporary Korean handmade papers produced in different workshops [42]. Besides dyed samples using natural or synthetic dyes or pigments for specific calligraphy, fine art or crafts applications, most of the sample are undyed and the $L^{*} a^{*} b^{*}$ colour space (Fig. 2) of Hanji without dying process (227 samples) is within a colour gamut of $L^{*}$ (69.9-95.9), $a^{*}[(-3)-3], b^{*}(0-20)$. The lightness values range from 69.9 to 95.9 with an average value of 88.2. The colour represention can be classified into groups with $L^{*}$ value ranging from low, medium and high (Fig. 2). As for $a^{*}$ and $b^{*}$ coordinate (Additional file 1: Figure S2), all the papers are located on the $-a^{*}+b^{*}$ and $+a^{*}+b^{*}$ space with $-a^{*}+b^{*}$ space having the majority. The yellowness is the main characteristic with the $b^{*}$ ranging from 0 to 20: most clustered within 1.6-7.88 and 7.8814.16 range. For coordinate $a^{*}$, the majority clustered in the range -1.43 to 0.04 . The distribution in $a^{*} b^{*}$ space indicates that most Hanji represent more greenness than redness in colour representation. Some samples with less $L^{*}$ values were also observed which all underwent treatment process such as mix with coloured clay, or black bark. Although practiced conservators can compare colour and colour changes by their experience, the quantified colour space is more convenient to compare colours and to trace colour changes in conservation applications [43]. Furthermore, the paper colour space information could also be used for classification of papers with different origins when obtained large data set $[44,45]$.

The $\mathrm{pH}$ of Hanji ranged from 5.3 to 9.8 with $98.3 \%$ having $\mathrm{pH}$ value above 6 . A total of $83.3 \%$ were acid-free 


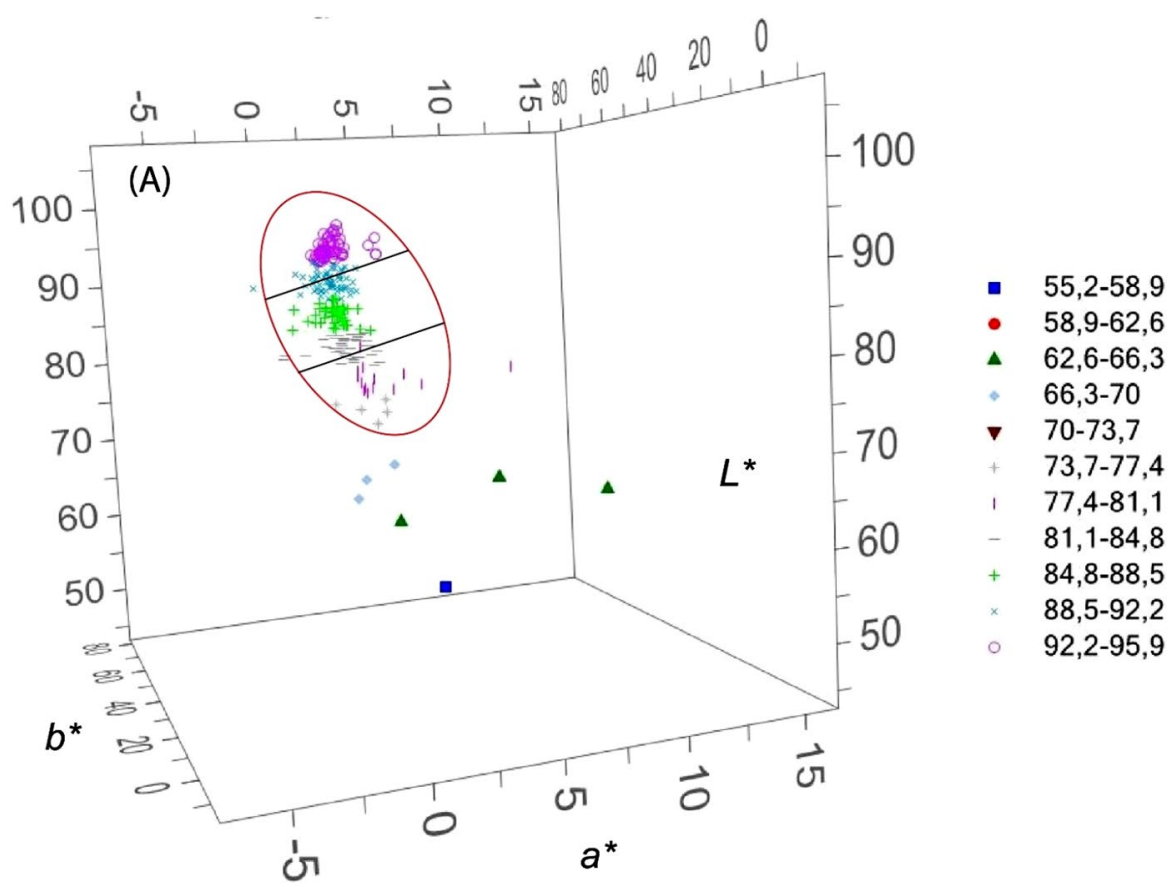

Fig. 2 The $L^{*} a^{*} b^{*}$ colour space of studied modern Hanji samples

papers with $\mathrm{pH}$ value above 7 (Fig. 3). These general features are likely caused from the treatment process that use plant ash, sodium carbonate $\left(\mathrm{Na}_{2} \mathrm{CO}_{3}\right)$ or sodium hydroxide $(\mathrm{NaOH})$ which create alkaline conditions. Plant ash was traditionally utilized to create a mild alkali cooking solution. But nowadays only 13\% Hanji are still cooked traditionally with plant ash which takes lots of time and energy to maintain, while most are treated with chemical reagents such as sodium carbonate (mild alkali solution that can minimize the damage to the fiber, used to produce high quality Hanji) or sodium hydroxide (strong alkali solution, used for lower quality Hanji) which helps to shorten the preparation time.

Grammage is an intrinsic physical characteristic of paper which defined as weight in grams per square meter (GSM). Grammage of handmade paper greatly influences the stiffness and the strength of the paper thus determines different paper applications. It can be seen from Fig. 3 that more than half of Hanji samples are with grammage between 20 and 40 GSM while $24.3 \%$ are between 40 and 60 GSM. Only $5.8 \%$ have grammage more than $80 \mathrm{GSM}$. As for the thickness, the majority (40.8\%) are in the range of $100-150 \mu \mathrm{m}$ (Fig. 3). Eleven (11) samples have thickness less than $50 \mu \mathrm{m}$ with $32.5 \mu \mathrm{m}$ as the minimum value (thin, soft and transparent Hanji).

Different workshops manufactured paper samples with different processes and therefore influenced their features. For instance, most Hanji samples from workshop 6 and 11 (Mungyeong Jeontong Hanji \& Shinhyeonse Jeontong Hanji) have high paper strength (Additional file 1: Figure S3). Workshop 8 and 9 (Cheongsong Jeontong Hanji \& Parkseonghwan Jeontong Hanji) produced Hanji with low basic weight while workshop 2 and 3 (Wonju

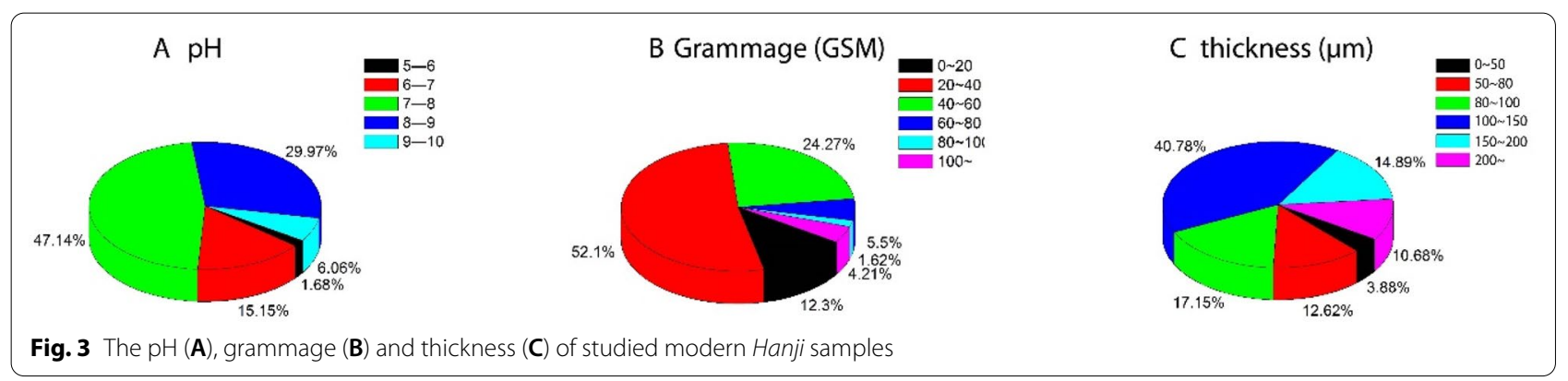


Hanji \& Wonju Jeontong Hanji) produced mainly dyed papers (Additional file 1: Figure S3).

\section{Different sheet formation: Heullimtteugi vs Gadumtteugi}

Different sheet formation methods greatly influenced the fiber orientation of handmade papers $[46,47]$. As is shown in Fig. 4, the fiber orientation can be clearly observable especially with thin and transparent Hanji samples, for instance, Fig. 4A shows a thin Heullimtteugi Hanji (thickness $43.6 \mu \mathrm{m}$ ) and the intercross of fibers is clearly depicted: the dense crisscrossed fibers resemble the character '\#'. Figure 4B shows a thin Gadumtteugi Hanji (thickness $34.3 \mu \mathrm{m}$ ) with strong fiber alignment in one direction. Gadumtteugi can produce strong fiber orientation papers (Fig. 4B, D) while Heullimtteugi produces papers with fiber orientation more evenly distributed (Fig. 4A, C).

The fiber orientation produced with different methods influenced paper physical properties [47]. The tensile strength is mostly in the range of $352.8-3000 \mathrm{~N} / \mathrm{m}$ (grain-direction) and 183.1-2000 N/m (cross-direction) (Fig. 5A, thick paper board samples not counted). It is interesting to note that the majority of Hanji $(75.7 \%)$ hold the property that the tensile strength for grain-direction is higher than cross-direction with the reverse ones mostly being Heullimtteugi Hanji. The Heullimtteugi Hanji showed a proportion of $50 \%$ with the ratio of tensile strength grain-direction/cross-direction greater than 1 while this proportion for Gadumtteugi Hanji is 95\%. The result indicates that the alignment of the fiber direction of Heullimtteugi Hanji present more diversity thus gives paper strength in both directions; the Gadumtteugi Hanji has more consistency in fiber alignment in one direction that cause different paper strength in grain and cross directions.

The folding endurance varies from several times (minimum 1.2 times) to thousand times (maximum 1681.1 times) (Fig. 5B), 60\% of the samples have the folding endurance between 1.2 and 500 times. Almost all the Gadumtteugi Hanji were distributed under the diagonal line in Fig. 5B which means the ratio of folding endurance grain-direction/cross-direction is higher than 1 . However, the Heullimtteugi Hanji presented quite different profiles with $56.7 \%$ above and $44.3 \%$ under the
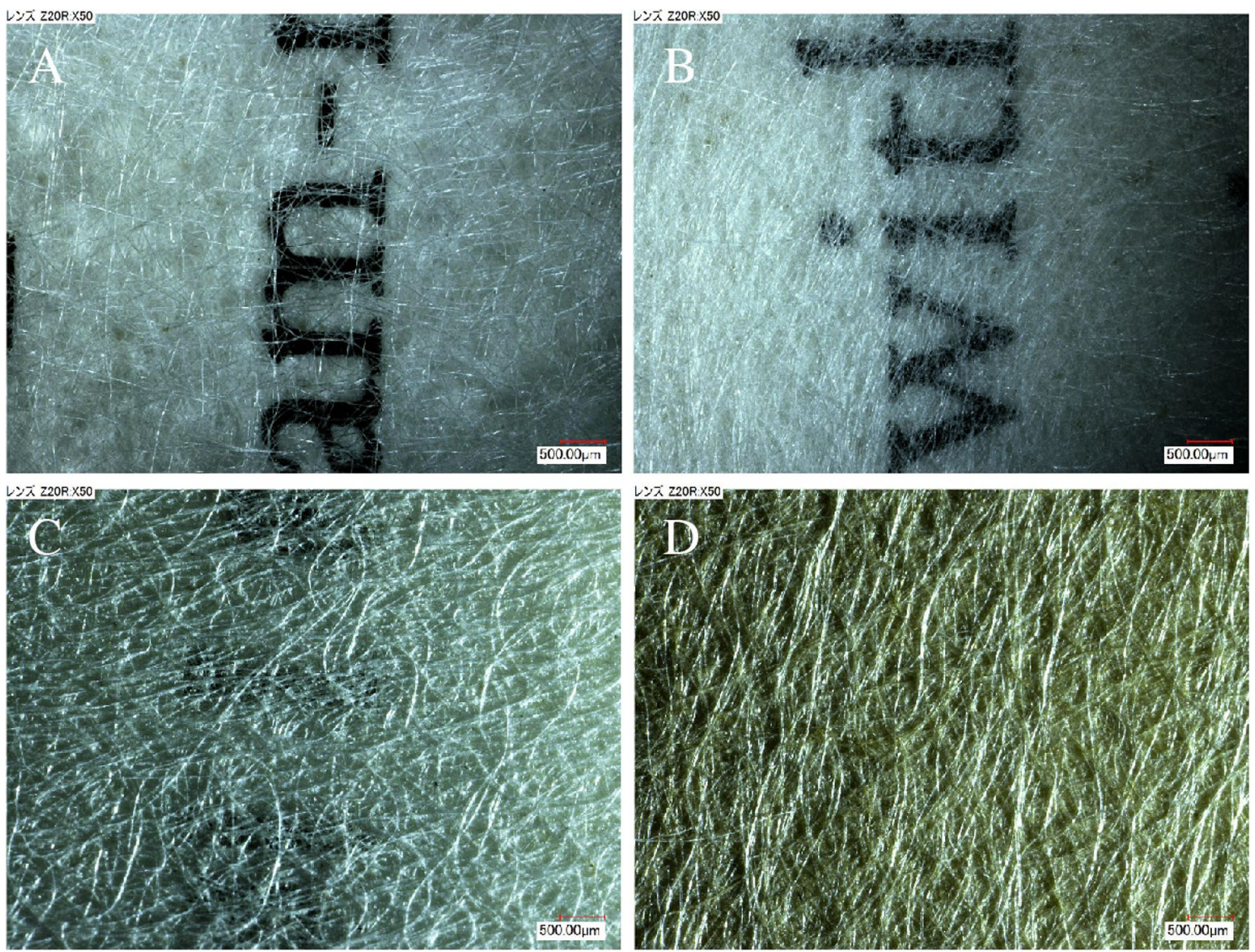

Fig. 4 The microscopy observation of fiber orientations. A, C are examples of Heullimtteugi Hanji with dense crisscrossed fiber orientation; B, D are examples of Gadumtteugi Hanji with strong aligned fiber orientation 

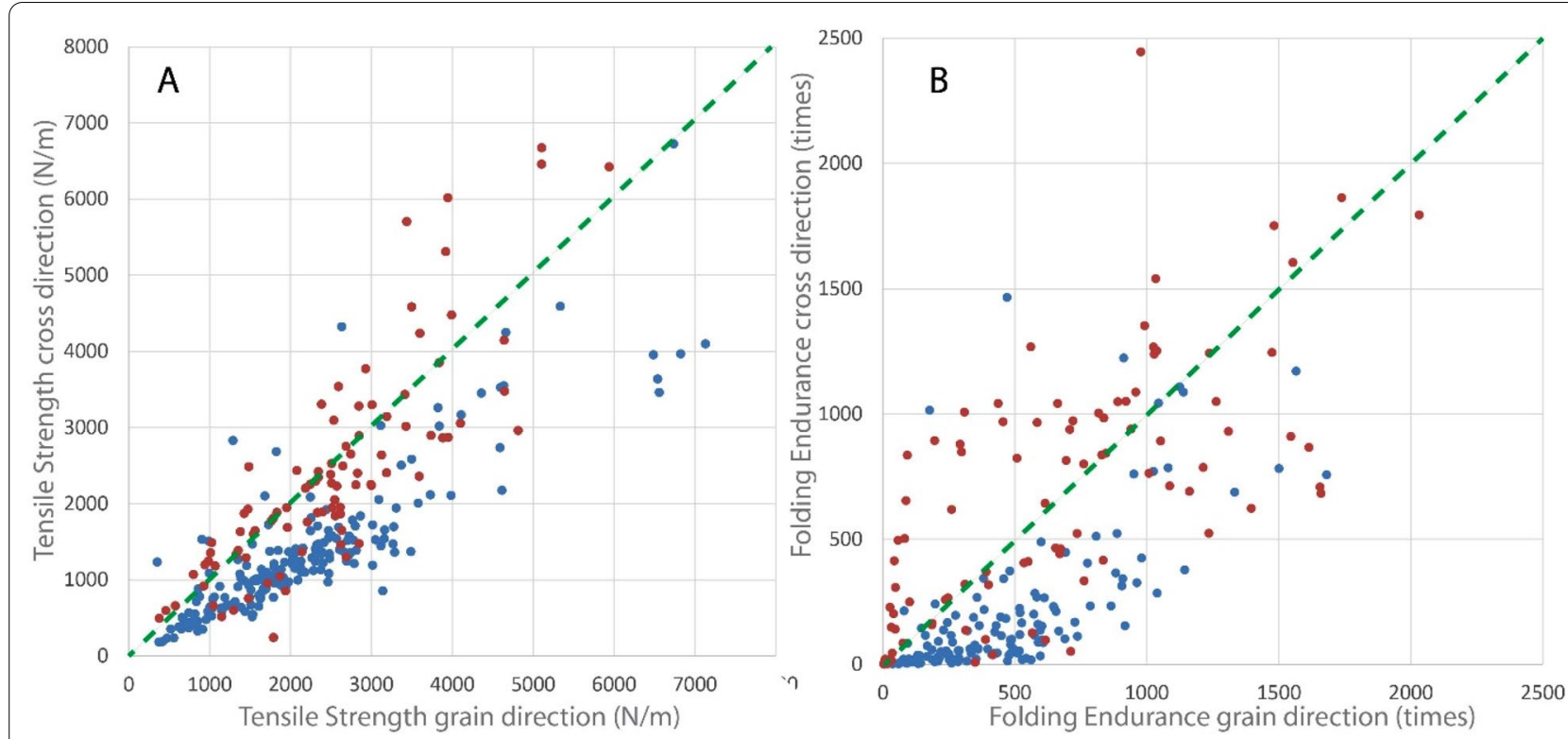

Fig. 5 The tensile strength (A) and folding endurance (B) of Hanji in grain direction and cross direction. In $\mathbf{A}$ and $\mathbf{B}$, red dots are Heullimtteugi Hanji and blue dots are Gadumtteugi Hanji

diagonal line. Heullimtteugi sheet formation tend to produce more even dispersed fiber orientation paper which reflected by its tensile strength and folding endurance in both cross and grain directions. This point could be one consideration when choosing Hanji for applications requiring frequent folding in both directions. Besides the manufacturing methods, Dochim (calendering) also greatly improves the tensile strength and folding endurance of the papers. For instance, calendered sample 1-15 showed improved strength compared to those papers having similar basic weight and thickness such as sample 10-08, 5-09 and 5-21 (Additional file 1: Table S1).

The density of paper is influenced by the type of fiber and paper treatments. The correlation between grammage and thickness of Gadumtteugi and Heullimtteugi Hanji was calculated and shown in Fig. 6. From the fitted curve of grammage $(w)$ and thickness $(t)$, the density $(\rho)$ for Hanji can be calculated using Eq. 1. The grammage
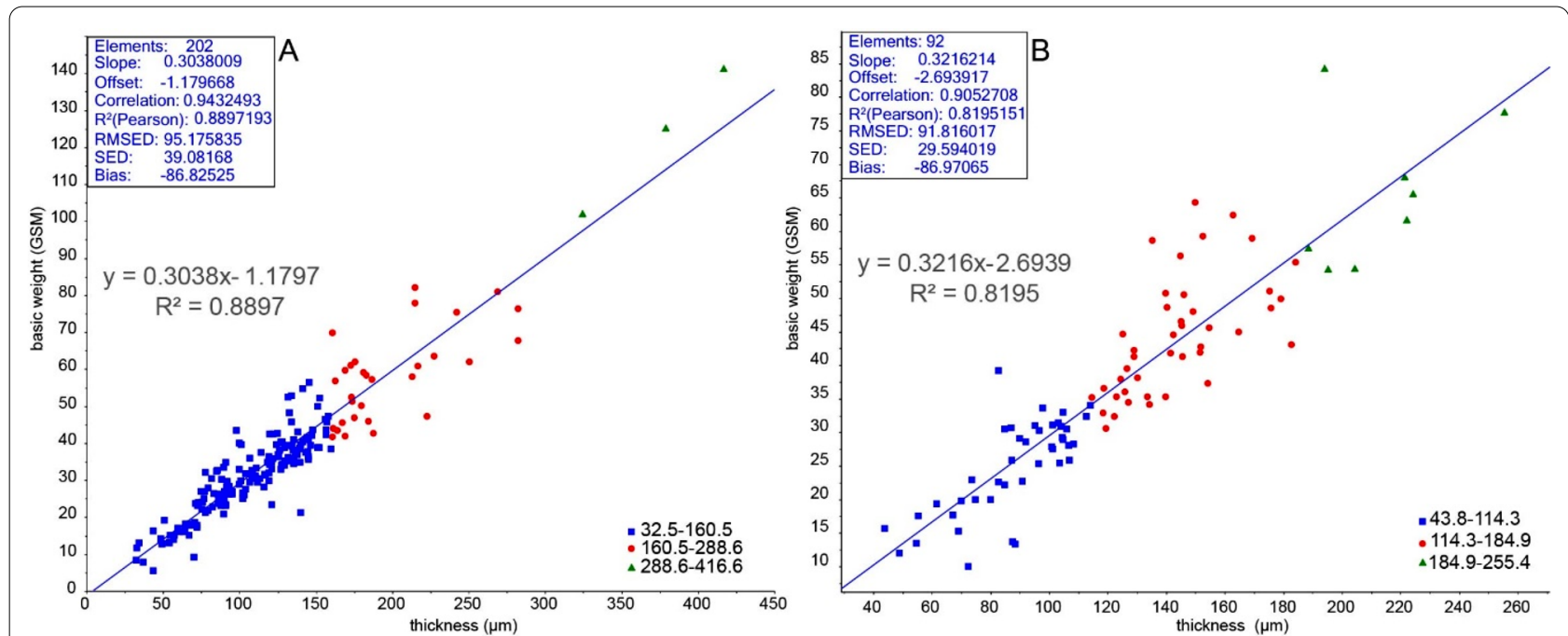

Fig. 6 The fitted curve for the correlation between the grammage and thickness of A Gadumtteugi Hanji and B Heullimtteugi Hanji. The density of Gadumtteugi Hanji and Heullimtteugi Hanji is calculated in Eq. 3, 4, respectively 
$(w)$ equals to density ( $\rho$ ) multiplied by thickness (Eq. 2) which is the slope of the correlation (Fig. 6). The calculated density of Gadumtteugi Hanji is $304 \mathrm{~kg} / \mathrm{m}^{3}$ while the density for Heullimtteugi Hanji is $322 \mathrm{~kg} / \mathrm{m}^{3}$ (Fig. 6 , Eq. 3 and 4,): Heullimtteugi sheet formation tend to make denser paper compared to Gadumtteugi sheet formation. Further principal component analysis (PCA) of data performed using tensile strength and folding endurance values also showed well separated locations in the score plots, discriminating different type of Hanji (Additional file 1: Figure S4).

$$
\begin{aligned}
& \rho=w / t\left(\mathrm{~kg} / \mathrm{m}^{3}\right) \\
& w=\rho t\left(\mathrm{~g} / \mathrm{m}^{2}\right) \\
& w=0.304 t-1.18(\text { Gadumtteugi Hanji }) \\
& w=0.322 t-2.69(\text { Heullimtteugi Hanji) }
\end{aligned}
$$

Paper property data analysis showed that the sheet formation methods (Heullimtteugi vs Gadumtteugi) influenced the fiber orientation, tensile strength, folding endurance and density of Hanji. The fiber orientation of Heullimtteugi Hanji is more evenly distributed than that of Gadumtteugi Hanji, which gives paper strength in both directions. For instance, Heullimtteugi Hanji shows profiles of more evenness, better folding endurance and even tensile strength in all fibre direction and consequently Heullimtteugi Hanji is a better choice for applications that requires good folding endurance or even strength in both directions; meanwhile, Gadumtteugi Hanji with strong fiber orientation is more suitable for conservation or strengthening of book spine which requires frequent folding in one direction. In practice, however, it is noted that 212 out of 309 samples (69\%) were made by Gadumtteugi while only 97 samples (31\%) by Heullimtteugi which showed that the tradition of Heullimtteugi is less practiced since it requires intensive labor and virtuosity.

\section{The chemical profiles of raw fibers}

Most modern Korean handmade papers collected in the reference sample book were made of paper mulberry (Korean name Dak) fibers while bark fibers from other plants such as gampi and mutsumata have also been used in Hanji making. Their chemical profiles were analysed by Py-GC/MS. They are mainly composed of cellulose that resulted in numerous peaks generated from the thermal carbohydrate backbone degradation. Levoglucosan, a six-carbon oxygenate, is the most abundant primary product from cellulose pyrolysis, a characteristic feature of cellulosic material pyrolysis that has been previously elaborated (Fig. 7A) [3, 40, 48, 49].

Besides those cellulose pyrolysis products, other components such as lignin monomers and terpenic compounds were characterized in Hanji raw fibers. Lignin is a polyphenol produced by oxidative condensation of three phenylpropanoid monomers, namely p-coumaryl, coniferyl and sinapyl alcohols. The phenyl moieties of such compounds differ in the hydroxy and methoxy substituents and classified as hydroxyphenyl $(\mathrm{H})$, guaiacyl (G) and syringyl (S) units [50]. Within the same region, lignin markers of phenolic compounds of different types were identified that mainly composed of $\mathrm{G}$ and $\mathrm{S}$ moieties (Fig. 7B; Table 1). It is noted that Hanji made from bast fibers of gampi (H1-05) and mitsumata (H1-06) present much higher intensity of lignin pyrolysis produces especially for compound 12 (demonstrated by $\mathrm{m} / \mathrm{z} 180$ in Fig. 7C), compound 13, 15, 19 (demonstrated by $\mathrm{m} / \mathrm{z} 180$ in Fig. 7C) and compound 14, 18 (demonstrated by $\mathrm{m} / \mathrm{z}$ 196 in Fig. 7C). While these lignin monomers were less intensive in Hanji made from paper mulberry fiber. The use of strong alkali solution $\mathrm{NaOH}$ during cooking process damaged the fiber and reduce much of lignin component as can be observed from sample Hanji H1-08 that shows almost complete removal of the lignin monomers (Fig. 7C) (the paper treatment conditions can be found at Table 2 as well as Additional file 1: Table S1).

Terpenic compounds with the characteristic ions of $\mathrm{m} / \mathrm{z}$ at $218,203,189$ was identified and characterized in the pyrolysis of Hanji that are in accord to papermaking fibers from the Moraceae family [40, 41, 51, 52]. It can be seen from the total ion chromatogram (TIC) that these terpenic compounds elute in the plant marker region (defined as region of interest, ROI) at a comparatively high temperature (Fig. 7A). The dominant structures obtained from the pyrolysis of Hanji identified in this region consist of triterpene of oleanane and ursane structures (Table 1). As can be seen from its extracted ion chromatograms (EIC) in Additional file 1: Figure S5, the distribution of the terpene compounds with the selected ions ( $\mathrm{m} / \mathrm{z}$ at 218, 203 and 189) constitute the main compounds in the plant marker region (Table 2).

A general behaviour observed during the pyrolysis of Hanji with different fiber sources showed that paper mulberry fiber presented high concentrations of terpene compounds while gampi and mitsumata fiber mainly generated compounds of phytosterols in the defined ROI (Additional file 1: Figure S6).The characterization of paper mulberry fibers from those of gampi and mitsumata fibers in Japanese handmade papers by Py-GC/ MS was previously studies with similar observations in compound distributions compared to Korean handmade 


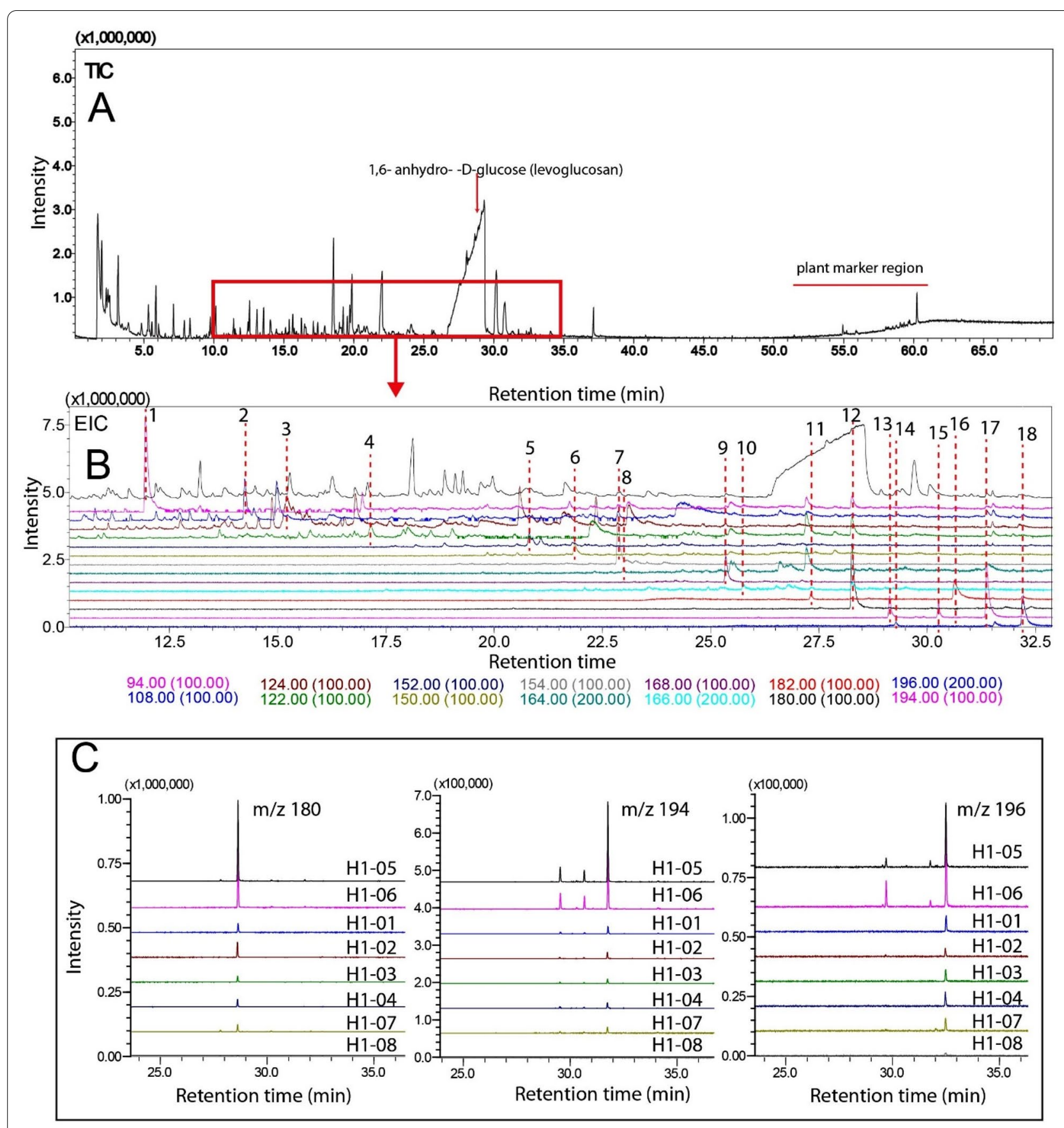

Fig. 7 The TIC chromatogram of Hanji pyrolysis products (A), the TIC/EIC chromatogram of lignin monomers (B) and EIC chromatogram of lignin monomers (C). For compound assignments, see Table 1. Detailed information of sample H1-01 to H1-08 is listed in Table 2

papers $[3,40]$. Furthermore, the Hanji pyrolysis component of lignin monomers has been characterized which also showed different distributions between paper mulberry fiber and gampi, mitsumata fibers (Fig. 7C). The difference of lignin monomers increased the dimension of the data that can be used for handmade paper fiber identification and discrimination [3]. The lignin monomer content may also provide information to estimate handmade paper treatment process (e.g., mild alkali treatment or modern strong alkali agent treatment) that can be used in study and identification of ancient handmade papers. 
Table 1 Assignment of Pyrolysis of Hanji plant markers

\begin{tabular}{|c|c|c|c|c|c|}
\hline No. & Ret. time (min) & MW & Main ions & Attribution & Type \\
\hline 1 & 11.97 & 94 & $94,66,55,58$ & Phenol & $\mathrm{L}-\mathrm{H}$ \\
\hline 2 & 14.23 & 108 & $108,107,79,85$ & 2-Methylpheno & $\mathrm{L}-\mathrm{H}$ \\
\hline 3 & 15.19 & 124 & $124,109,81,95$ & Guaiacol & $L-G$ \\
\hline 4 & 17.17 & 122 & $122,107,91,77$ & 2,6-Dimethylphenol & $\mathrm{L}-\mathrm{H}$ \\
\hline 5 & 20.82 & 152 & $152,137,122,128$ & 4-Ethylguaiacol & $L-G$ \\
\hline 6 & 21.86 & 150 & $150,135,107,77$ & 4-Viny lguaiacol & $L-G$ \\
\hline 7 & 22.86 & 154 & $154,139,111,93$ & 2,6-Dimethoxyphenol & $L-G$ \\
\hline 8 & 22.93 & 164 & $164,149,103,121$ & Eugenol & $L-G$ \\
\hline 9 & 25.36 & 168 & $168,153,125,107$ & 2,6-Dimethoxy-4-methyl-phenyl & L-S \\
\hline 10 & 25.77 & 166 & $166,137,122,94$ & Homovanillin & $L-G$ \\
\hline 11 & 27.33 & 182 & $182,167,122,136$ & 4-Ethyl-2,6-dimethoxypheno & L-S \\
\hline 12 & 28.28 & 180 & $180,165,137,91$ & 2,6-Dimethoxy-4-vinylphenol & L-S \\
\hline 13 & 29.12 & 194 & $194,91,119,131$ & 4-Allyl-2,6-dimethoxyphenol & L-S \\
\hline 14 & 29.22 & 196 & $196,167,110,103$ & 2,6-Dimethoxy-4propylpheno & L-S \\
\hline 15 & 30.26 & 194 & 194, 179, 151, 119 & cis-2,6-Dimethoxy-4 propenyl-phen & $L-S$ \\
\hline 16 & 30.62 & 182 & $182,181,167,91$ & Syringaldehyde & L-S \\
\hline 17 & 31.38 & 194 & $194,179,119,91$ & trans-2,6-Dimethoxy-4-propenylphe & $L-S$ \\
\hline 18 & 32.22 & 196 & $196,181,153,123$ & Acetosyringone & $L-S$ \\
\hline 19 & 54.37 & 408 & $218,203,189,119$ & Oleanane-2,12-diene & $\mathrm{T}-\mathrm{O}$ \\
\hline 20 & 54.96 & 408 & $218,189,119,95$ & Urs-2,12-diene & $\mathrm{T}-\mathrm{U}$ \\
\hline 21 & 54.92 & 412 & $135,143,394,81$ & Stigmasta-4,6-dien-3-ol & S \\
\hline 22 & 55.05 & - & $218,189,95,119$ & Ursane structure NA & $\mathrm{T}-\mathrm{U}$ \\
\hline 23 & 55.19 & 396 & $145,81,396,275$ & stigmasta-3,5-diene NA & S \\
\hline 24 & 55.27 & - & $218,189,203,95$ & Ursane structure NA & $\mathrm{T}-\mathrm{U}$ \\
\hline 25 & 55.90 & 408 & $218,107,119,105$ & Ursane structure NA & $\mathrm{T}-\mathrm{U}$ \\
\hline 26 & 58.20 & 424 & $218,203,95,119$ & Oleanane-12-en-3-one & $\mathrm{T}-\mathrm{O}$ \\
\hline 27 & 58.49 & 426 & $218,203,189,95$ & Oleanane-12-en-3-ol & $\mathrm{T}-\mathrm{O}$ \\
\hline 28 & 58.75 & 424 & $218,95,109,107$ & Urs-12-en-3-one & $\mathrm{T}-\mathrm{U}$ \\
\hline 29 & 59.05 & 426 & $218,95,107,121$ & Urs-12-en-3-ol & $T-U$ \\
\hline 30 & 59.17 & 410 & $174,410,159,161$ & Stigmasta-3,5-dien-7-one & S \\
\hline 31 & 59.70 & 468 & $218,203,189,95$ & Oleanane-12-ene-3-acetate & $\mathrm{T}-\mathrm{O}$ \\
\hline 32 & 60.22 & 468 & $218,189,95,135$ & Urs-12-ene-3-acetate & $\mathrm{T}-\mathrm{U}$ \\
\hline
\end{tabular}

$L$ lignin; $H$ hydroxypheny; G: guaiacy; (L-)S syringy; $T$ terpene; $O$ oleanane; $U$ ursane; $S$ stigmasta

Table 2 The fiber composition, making method of the test samples from $\mathrm{H} 1-01$ to $\mathrm{H} 1-08$

\begin{tabular}{|c|c|c|c|c|c|c|c|c|}
\hline No. & Fiber composition & Cooking condition & Mucilage & Method & Bleaching & Beating & $\mathrm{pH}$ & Use \\
\hline $\mathrm{H} 1-01$ & $100 \%$ Dak & Yukjae & Dakpul & G & Non & K & 8.7 & Conservation \\
\hline $\mathrm{H} 1-02$ & $96 \%$ Dak + 4\%Anpi & Yukjae & Dakpul & $H$ & Non & K & 9.8 & Conservation, art work \\
\hline $\mathrm{H} 1-03$ & $96 \%$ Dak+ 4\%Anpi & Yukjae & Dakpul & $H$ & Non & K & 5.8 & Conservation \\
\hline $\mathrm{H} 1-04$ & $96 \%$ Dak+ 4\%Anpi & Yukjae & Dakpul & $H$ & Non & K & 8.1 & Conservation \\
\hline $\mathrm{H} 1-05$ & 100\% Anpi & $\mathrm{Na}_{2} \mathrm{CO}_{3}$ & Dakpul & G & $\mathrm{NaClO}$ & $N$ & 7.4 & Printmaking \\
\hline $\mathrm{H} 1-06$ & 100\% Samjidak & $\mathrm{Na}_{2} \mathrm{CO}_{3}$ & Dakpul & G & Non & $N$ & 6.5 & Calligraphy \\
\hline $\mathrm{H} 1-07$ & 100\% Dak & $\mathrm{Na}_{2} \mathrm{CO}_{3}$ & Dakpul & G & $\mathrm{NaClO}$ & K & 7.5 & Crafts \\
\hline $\mathrm{H} 1-08$ & $100 \%$ Dak & $\mathrm{NaOH}$ & PAM & G & $\mathrm{NaClO}$ & $K$ & 5.8 & Paintings \\
\hline
\end{tabular}


In East Asia, the inner bark of paper mulberry has been widely used as raw material for hand papermaking. For instance, paper mulberry fiber has been used in Korean handmade papers (Hanji) and Japanese handmade papers (Washi). Since they are made from quite similar species, no difference was clearly evidenced by microscopic observation to distinguish papers from these two areas. The pyrolysis profiles of Hanji are also quite similar in chemical compositions to those of Washi as both of them use fibres from the species in Broussonetia genus [3]. The similarity can also be observed from their similar compound distribution patterns in the ROI demonstrated in Additional file 1: Figure S7. Nevertheless, a difference in the intensity ratio of compound X1 (sterol compound tentatively identified as lanosta-8,24-dien-3-ol, acetate) and compound T1 (oleanane-12-ene-3-acetate, No.31 in Table 1) has been noticed with Hanji having relative higher ratio when both compounds were detected (Additional file 1: Figure S8).

\section{Conclusion}

This study reports the characterization of Korean handmade papers constituted in a well edited Hanji reference book. It was observed that the difference in material preparing and paper making craft lead to different paper structure which is statistically reflected in their physical properties. The structure differences determine paper performance and applications as a general connection between the crafting, measured data and potential significance. The chemical composition of Hanji raw fiber materials of paper mulberry, gampi and mitsumata has been analysed by Py-GC/MS that showed different profiles of lignin monomers and terpenic compounds. The use of strong alkali solution was observed to greatly eliminate the lignin component. The difference of Hanji and Washi from a relative intensity ratio of two compounds in the plant marker region is observed in their pyrolysis results which could be used in ancient paper samples differentiation with further proper method development. These quantified data analysis and descriptions serves as a way to retrieve paper crafting information as well as providing potential significance on their applications which are useful to get acquainted with modern Korean handmade papers for different applications.

This report is the first study on well-defined Hanji samples in large quantities, forming a base for further study and comparison of handmade papers in East Asian region. It also contributes to a better understanding of Hanji properties for cultural relics applications, as well as improves knowledge on handmade papers from the Korean peninsula. In a general sense for handmade paper study, this investigation pointed out what benefit can be derived from protocol well-defined handmade papers in large quantities as well as stressed a situation where these samples are currently rare and lacking in scientific research on handmade papers.

\section{Supplementary Information}

The online version contains supplementary material available at https://doi. org/10.1186/s40494-021-00570-9.

Additional file 1: Figure S1. A map of Hanji workshop locations in Korea. The map was according to the Hanji making workshop information in the four-volume of reference handmade paper sample collection book Hanji, Korean handmade paper [42]. Figure S2. (B) and (C) are projections in $\mathrm{a}^{*}$ and $b^{*}$ space of colour gamut from the studied Hanji samples. Figure S3. Scores plot and loadings plots in PCA analysis of the general property data in Table S1. The variation factors of FC, CC, FM, SFM, BL, BM, DY, Do has been digitalized as input number of $1,2,3 \ldots$. And the weightings of the variables were using 1/STD, where STD stands for standard deviation, for principal component analysis. Figure S4. Scores plot in PCA analysis of the mechanical property of Hanji with mappings of tensile strength value in grain-direction (A) and cross-direction (B), folding endurance value in grain-direction (C) and cross-direction (D). PCA was performed with tensile strength and folding endurance data values without normalization. In general, the Gadumtteugi $(\mathrm{G})$ and Heulimtteugi $(\mathrm{H})$ Hanji were clustered into two parts with Heulimtteugi Hanji locate in the positive PC2 coordinate while Gadumtteugi Hanji situated in the negative PC2 coordinate: Mapping with the tensile strength value (grain direction), within each type, they can be classified into three groups with the tensile strength ranging from low, medium and high (A); while mapping with the cross direction value (B), Heulimtteugi Hanji can still be classified into three groups meanwhile the Gadumtteugi Hanji is divided either low or high types; mapping with the folding endurance value (grain direction) (C), the low and medium value were clustered together; while mapping with cross direction value showed that Gadumtteugi Hanji has weak values in the cross direction folding endurance (D). Figure S5. The total ion chromatogram (TIC) of Hanji sample made with paper mulberry fibers (A) and the extracted ion chromatogram (EIC) of pyrolysis products of terpenic compounds distribution pattern exampled with paper mulberry as raw material (B). For compound assignment, see Table 1. Figure S6. The total ion chromatogram (TIC) of Hanji sample made with paper mulberry fibers (H1-01), gampi fibers (H1-05) and mitsumata fibers (H1-06). Figure S7. (A) is the TIC chromatogram while (B) is the EIC $\mathrm{m} / \mathrm{z}$ at 218 . In (A) and (B), (I) is Hanji and (II) is Washi. (C) is the enlarged demonstration of the region in (B), (D) is the mass spectra of compound $X 1$ after background subtraction and $(E)$ is the NIST library search results with high match factor. Figure S8. The ration of the EIC ( $\mathrm{m} / \mathrm{z}$ at 218$)$ area of $X 1 / T 1$ (in percentage). The data are from 12 test of Hanji papers and 12 test of Washi papers that have signals of $\mathrm{X} 1$ and $\mathrm{T} 1$ at $\mathrm{EIC} \mathrm{m/z}$ at 218 and respective retention time at 59.6 min and $59.7 \mathrm{~min}$, respectively. Table $\mathbf{S} \mathbf{1}$. Some general property data of the handmade paper samples attached in the four-volume Hanji reference book book that data analyses have been performed in this study.

\section{Acknowledgements}

B.H. thanks Ms Qiyun Han, Ms Liuyi Ke (objective conservator), and Prof. Yimin Yang (University of Chinese Academy of Sciences) for constructive suggestions.

\section{Authors' contributions}

Conceptualization: $\mathrm{BH}, \mathrm{L}-\mathrm{BV}$; methodology: $\mathrm{BH}, \mathrm{H}-J \mathrm{~K}, \mathrm{SS}, \mathrm{MS}$; investigation: $\mathrm{BH}, \mathrm{L}-\mathrm{BV}, \mathrm{H}-\mathrm{JK}, \mathrm{BL}, \mathrm{SS}, \mathrm{MS}$; funding acquisition: $\mathrm{BH}$; writing-original draft: $\mathrm{BH}$; writing-review and editing: $\mathrm{BH}, \mathrm{L}-\mathrm{BV}, \mathrm{H}-\mathrm{JK}, \mathrm{BL}, \mathrm{SS}, \mathrm{MS}$. All authors read and approved the final manuscript.

Funding

B. H. is grateful to the National Social Science Fund for help. 


\section{Availability of data and materials}

The data used in the study are available from the corresponding author on reasonable request.

\section{Declarations}

\section{Competing interests}

The authors declare no competing interests.

\begin{abstract}
Author details
'Department of Archaeology and Anthropology, School of Humanities, University of Chinese Academy of Sciences, Beijing 100049, China. ${ }^{2}$ Centre de Recherche Sur La Conservation (USR 3224), Muséum National d'Histoire Naturelle, Ministère de La Culture, CNRS, 75005 Paris, France. ${ }^{3}$ Department of Forest Products and Biotechnology, Kookmin University, Seoul 02707, Republic of Korea. ${ }^{4}$ Research Center for World Buddhist Cultures, Ryukoku University, Kyoto 600-8268, Japan.
\end{abstract}

Received: 18 May 2021 Accepted: 2 August 2021

Published online: 19 August 2021

\section{References}

1. Tsien T-H. Raw materials for old papermaking in China. J Am Orient Soc. 1973;93:510-9. https://doi.org/10.2307/600169.

2. Shi JL, LiT. Technical investigation of 15th and 19th century Chinese paper currencies: fiber use and pigment identification. J Raman Spectrosc. 2013;44(6):892-8. https://doi.org/10.1002/jrs.4297.

3. Han B, Vial J, Sakamoto S, Sablier M. Identification of traditional East Asian handmade papers through the multivariate data analysis of pyrolysis-GC/ MS data. Analyst. 2019;144(4):1230-44. https://doi.org/10.1039/C8AN0 $1898 \mathrm{G}$.

4. Luo Y, Cigić IK, Wei Q, Strlič M. Characterisation and durability of contemporary unsized Xuan paper. Cellulose. 2021;28(2):1011-23. https://doi. org/10.1007/s10570-020-03554-3.

5. Chen G, Katsumata KS, Inaba M. Traditional Chinese papers, their properties and permanence. Restaurator Int J Preserv Libr Arch Mater. 2003; 24(3):135-144. https://doi.org/10.1515/REST.2003.135

6. Lee K, Enomae T, Inaba M. Comparison of degradation behaviour of the painting paper in Japanese scrolls for moist heat and sealed tube ageing methods. Stud Conserv. 2021. https://doi.org/10.1080/00393630.2020. 1846931.

7. Masuda K. Japanese paper and Hyōgu. Paper Conserv. 1985;9(1):32-41. https://doi.org/10.1080/03094227.1985.9638467.

8. Jeong M-J, Kang K-Y, Bacher M, Kim H-J, Jo B-M, Potthast A. Deterioration of ancient cellulose paper, Hanji: evaluation of paper permanence. Cellulose. 2014;21(6):4621-32. https://doi.org/10.1007/s10570-014-0455-4.

9. Song M, Munn J. Permanence, durability and unique properties of Hanji. In: The book and paper group annual (2004). Princeton: Citeseer; 2005. p. 127-36.

10. Yum H. Traditional Korean papermaking: history, techniques and materials. Newcastle upon Tyne: Northumbria University; 2008.

11. Park Y-S. a history of Korean Paper. Study of Washi Cuture. 2004;12:32-48.

12. Choi J-I, Chung YJ, Lee KS, Lee J-W. Effect of radiation on disinfection and mechanical properties of Korean traditional paper. Hanji Radiat Phys Chem. 2012;81(8):1051-4. https://doi.org/10.1016/j.radphyschem.2011. 11.019 .

13. Jeong M-J, Bogolitsyna A, Jo B-M, Kang K-Y, Rosenau T, Potthast A. Deterioration of ancient Korean paper (Hanji), treated with beeswax: a mechanistic study. Carbohyd Polym. 2014;101:1249-54. https://doi.org/ 10.1016/j.carbpol.2013.10.033.

14. Jeon C. The effect of paper making methods and dochim of handmade Korean paper (Hanji) on the strength. J Korean Wood Sci Technol. 2002;30(2):134-43.

15. Kim HJ, Jo BM, Lee YM. The quality evaluation of Korean traditional Hanji by different sheet-making processes. J Korea Tech Assoc Pulp Paper Ind. 2004;36(5):44-52.
16. Cho J-H, Kim K-J, Park S-B, Eom T-J. Comparison of the functional properties of Hanji depending on the different manufacturing process. J Korea Tech Assoc Pulp Paper Ind. 2009;41(3):42-8.

17. Lee S-Ch. Hanji: everything you need to know about traditional Korean paper. Republic of Korea: Hyeonamsa Publishing Co., Ltd.; 2012.

18. Cheon C, Kim S-J, Jin Y-M. Properties of indigenous Korean paper (Hanji)Classification of Oebal (single frame) papermaking methods. J Korean Wood Sci Technol. 1999;27(1):88-104.

19. Paolo F, Calvini CF, Poggi CDPAN. Use of the Korean mulberry paper Hanji in book and paper conservation: when a traditional material meets new techniques. In: Adapt \& evolve 2015: East Asian materials and techniques in western conservation. Proceedings from the International Conference of the Icon Book \& Paper Group, London 8-10 April 2015. The Institute of Conservation: 2017: London; 2015. p. 110-7.

20. Jacobi E. Workshop Hanji papier maken: een verslag. Amsterdam: Au Courant-Restauratoren Nederland; 2016. p. 26-33.

21. $\mathrm{GolH}$, Jo AH, Ye JH, Jeong SH. Analysis of domestic research trends on Korean paper Hanji. J Conserv Sci. 2017;33(6):457-66. https://doi.org/10. 12654/JCS.2017.33.6.05.

22. Brown N, Lichtblau D, Fearn T, Strlič M. Characterisation of 19th and 20th century Chinese paper. Herit Sci. 2017;5(1):1-14. https://doi.org/10.1186/ s40494-017-0158-X.

23. Brown N, Coppola F, Modelli A, Amicucci F, Lichtblau D, Strlič M. Nondestructive collection survey of the historical Classense Library. Part I Paper Characterisation Herit Sci. 2020;8(1):1-11. https://doi.org/10.1186/ s40494-020-00432-w.

24. Dragojević A, Gregor-Svetec D, Tomažič JV, Lozo B. Characterization of seventeenth century papers from Valvasor's collection of the Zagreb Archdiocese. Herit Sci. 2021;9(1):1-20. https://doi.org/10.1186/ s40494-021-00507-2.

25. Jang KJ, Heo TY, Jeong SH. Classification option for Korean traditional paper based on type of raw materials, using near-infrared spectroscopy and multivariate statistical methods. BioResources. 2020;15(4):9045-58. https://doi.org/10.15376/biores.15.4.9045-9058.

26. Di Turo F, Mai C, Haba-Martínez A, Doménech-Carbó A. Discrimination of papers used in conservation and restoration by the means of the voltammetry of immobilized microparticles technique. Anal Methods. 2019:11(35):4431-9. https://doi.org/10.1039/C9AY00998A.

27. Vetter W, Frühmann B, Cappa F, Schreiner M. Materials and techniques used for the "Vienna Moamin": multianalytical investigation of a book about hunting with falcons from the thirteenth century. Herit Sci. 2021;9(1):1-17. https://doi.org/10.1186/s40494-021-00553-w.

28. Li HM, Severini L, Titubante M, Gong DC, Micheli L, Mazzuca C, Gong YX. Gellan gum hydrogel as an aqueous treatment method for Xuan paper. Restaurator Int J Preserv Libr Arch Mater. 2021;42(1):37-54. https://doi. org/10.1515/res-2020-0010.

29. Horst TH, Smith RD, Potthast A, Hubbe MA. Accelerated aging of deacidified and untreated book paper in 1967 compared with 52 years of natural aging. Restaurator. Int J Preserv Libr Arch Mater. 2020;41(3):131-52. https://doi.org/10.1515/res-2020-0006.

30. Luo $Y$, Zhang $X$. Effects of yellow natural dyes on handmade Daqian paper. Herit Sci. 2021;9(1):1-10. https://doi.org/10.1186/ s40494-021-00560-x.

31. Collings T, Milner D. The identification of oriental paper-making fibres. Paper Conserv. 1978;3(1):51-79. https://doi.org/10.1080/03094227.1978. 9638509.

32. Carr D, Cruthers N, Smith C, Myers T. Identification of selected vegetable textile fibres. Stud Conserv. 2008;53(sup2):75-87. https://doi.org/10.1179/ sic.2008.53.Supplement-2.75.

33. Haugan E, Holst B. Flax look-alikes: pitfalls of ancient plant fibre identification. Archaeometry. 2014;56(6):951-60. https://doi.org/10.1111/arcm. 12054.

34. Han B, Niang J, Rao H, Lyu N, Oda H, Sakamoto S, Yang Y, Sablier M. Paper fragments from the Tibetan Samye Monastery: clues for an unusual sizing recipe implying wheat starch and milk in early Tibetan papermaking. J Archaeol Sci Rep. 2021;36:102793.https://doi.org/10.1016/j.jasrep.2021. 102793.

35. Go IH, Jo AH, Jeong L, Heo TY, Cho K, Choi TH. Predictive model of geographical origin discrimination of paper mulberry and handmade paper using ICP-AES/MS and multivariate statistical analysis. J Cult Herit. 2021;49:222-8. https://doi.org/10.1016/j.culher.2020.12.004. 
36. LiT, Liu C, Wang D. Applying micro-computed tomography (micro-CT) and Raman spectroscopy for non-invasive characterization of coating and coating pigments on ancient Chinese papers. Herit Sci. 2020;8(1):116. https://doi.org/10.1186/s40494-020-00366-3.

37. Keheyan Y, Eliazyan G, Engel P, Rittmeier B. Py/GC/MS characterisation of naturally and artificially aged inks and papers. J Anal Appl Pyrol. 2009;86(1):192-9. https://doi.org/10.1016/j.jaap.2009.06.004.

38. Ohtani H, Komura T, Sonoda N, Taguchi Y. Evaluation of acidic paper deterioration in library materials by pyrolysis-gas chromatography. J Anal Appl Pyrol. 2009;85(1-2):460-4. https://doi.org/10.1016/j.jaap.2008.11.037.

39. Imn SY, Ji AY, Lee JS, Jeong HW. Material analysis and conservation treatment of sangryangmun in Jinnamgwan. Yeosu J Conserv Sci. 2020;36(3):213-24. https://doi.org/10.12654/JCS.2020.36.3.06.

40. Avataneo C, Sablier M. New criteria for the characterization of traditional East Asian papers. Environ Sci Pollut Res. 2017;24(3):2166-81. https://doi. org/10.1007/s11356-016-6545-0.

41. Han B, Vial J, Inaba M, Sablier M. Analytical characterization of East Asian handmade papers: a combined approach using Py-GCxGC/MS and multivariate analysis. J Anal Appl Pyrol. 2017;127:150-8. https://doi.org/ 10.1016/j.jaap.2017.08.013.

42. Kim H-J. Hanji, Korean handmade paper. Parkes: National Library of Australia; 2010

43. Tsai FW, Van der Reyden D. Analysis of modern Chinese paper and treatment of a Chinese woodblock print. Paper Conserv. 1997;21(1):48-62. https://doi.org/10.1080/03094227.1997.9638598.

44. Sakamoto S, Okada Y. Paper analysis and database of papers of the pelliot collection, Dunhuang manuscripts. In: International Conference on culture and computing (culture computing). Kyoto Japan: IEEE; 2015. https://doi.org/10.1109/Culture.and.Computing.2015.24.

45. Han B, Yimin Y, Huanhuan W, Changsui W. Prospects of technical authentication of bogus traditional Chinese paintings. China Cult Herit Sci Res. $2014 ; 4: 17$.
46. Masuda K. The findings from the survey of ancient document papers in the Shosoin treasure house and the present papers made by various hand sheet forming technique. Bull Off Shosoin Treasure House. 2010;32:85-95.

47. Han Y-H, Enomae T, Isogai A, Yamamoto H, Hasegawa S, Song J-J, Jang S-W. Traditional papermaking techniques revealed by fibre orientation in historical papers. Stud Conserv. 2006;51(4):267-76. https://doi.org/10. 1179/sic.2006.51.4.267.

48. Yao N, Wei S. Characterization and identification of traditional Chinese handmade paper via pyrolysis-gas chromatography-mass spectrometry. BioResources. 2021;16(2):3942. https://doi.org/10.15376/biores.16.2. 3942-3951.

49. Zhang $X$, Yang W, Dong C. Levoglucosan formation mechanisms during cellulose pyrolysis. J Anal Appl Pyrol. 2013;104:19-27. https://doi.org/10. 1016/j.jaap.2013.09.015.

50. Galletti GC, Bocchini P. Pyrolysis/gas chromatography/mass spectrometry of lignocellulose. Rapid Commun Mass Spectrom. 1995;9(9):815-26. https://doi.org/10.1002/rcm.1290090920.

51. Han B, Daheur G, Sablier M. Py-GCxGC/MS in cultural heritage studies: an illustration through analytical characterization of traditional East Asian handmade papers. J Anal Appl Pyrol. 2016;122:458-67. https://doi.org/10. 1016/j.jaap.2016.10.018.

52. Han B, Lob S, Sablier M. Benefit of the use of GCxGC/MS profiles for $1 D$ GC/MS data treatment illustrated by the analysis of pyrolysis products from east Asian handmade papers. J Am Soc Mass Spectrom. 2018;29(8):1582-93. https://doi.org/10.1007/s13361-018-1953-7.

\section{Publisher's Note}

Springer Nature remains neutral with regard to jurisdictional claims in published maps and institutional affiliations.

\section{Submit your manuscript to a SpringerOpen ${ }^{\odot}$ journal and benefit from:}

- Convenient online submission

- Rigorous peer review

- Open access: articles freely available online

- High visibility within the field

- Retaining the copyright to your article

Submit your next manuscript at $\boldsymbol{\Delta}$ springeropen.com 